\section{AORTIC VALVE PRESERVATION IN ACUTE TYPE A DISSECTION: IS IT SOUND?}

A series of 200 consecutive patients with acute Stanford type A dissection (157 men, $78 \%$; 43 women, $22 \%$ ) was analyzed to assess the validity of aortic valve preservation or repair. Indication for the operation in most cases was based on echocardiographic examination alone, to reduce the delay. In the majority of patients $(111 / 200,56 \%)$ the aortic valve was preserved or repaired if necessary. Aortic root replacement with a composite graft was performed in 66 of 200 patients (33\%), mainly because of an enlarged aortic anulus and sinus. Replacement of the aortic valve and the supracoronary ascending aorta was performed in 23 of 200 patients (12\%) with a diseased aortic valve (e.g., bicuspid valve) but an acceptable aortic sinus. Follow-up totaled 656 patient-years (maximum 14 years). Actuarial analyses as a function of type of repair and type of aortic valve provided the following probabilities plus or minus errors $(95 \%)$ : overall survival of the 200 patients was $78.3 \% \pm 2.9 \%$ after 30 days, $74.95 \% \pm 3.1 \%$ after 1 year, $67.9 \% \pm 3.6 \%$ after 5 years, and $48.5 \% \pm 6.1 \%$ after 10 years. Actuarial probability of freedom from reoperation for valve failuire in the complete series was calculated as $100.0 \% \pm 0.0 \%$ after 30 days, $99.3 \% \pm 0.7 \%$ after 1 year, $97.5 \% \pm 1.5 \%$ after 5 years, and $95.1 \% \pm 2.8 \%$ after 10 years. During long-term follow-up, there was no significant difference among groups with regard to structural deterioration, valve thrombosis, thromboembolic complications, anticoagulant-induced hemorrhage, and endocarditis. Freedom from valve failure and valve-related complications are similar for preserved, repaired, mechanical, and biologic valves. Valve-related reoperations are rare during at least 5 years of follow-up. Hence preservation or repair of the aortic valve can be recommended in the majority of patients with acute type A dissection. (J THORAC CARDIOVASC SURG 1996;111:381-91)

Ludwig K. von Segesser, MD (by invitation),

Enrico Lorenzetti (by invitation), Mario Lachat, MD (by invitation), Urs Niederhäuser, MD (by invitation), Mariette Schönbeck, MD

(by invitation), Paul R. Vogt, MD (by invitation), and Marko I. Turina, MD, Zurich, Switzerland
A cute aortic dissection ${ }^{1-3}$ remains a challenging entity in cardiovascular surgery despite the progress that has been made regarding its diagnosis and treatment. Transesophageal echocardiography, which can be done as a bedside procedure, not only speeds up the diagniostic process ${ }^{4,5}$ but also allows

From the Clinic for Cardiovascular Surgery, University Hospital, Zurich, Switzerland.

Read at the Seventy-fifth Annual Meeting of The American Association for Thoracic Surgery, Boston, Mass., April 23-26, 1995.

Address for reprints: Ludwig K. von Segesser, MD, FACS, Clinic for Cardiovascular Surgery, University Hospital, Rämistrasse 100, CH-8091 Zurich, Switzerland.

Copyright $(1996$ by Mosby-Year Book, Inc.

$0022-5223 / 96 \$ 5.00+0 \quad \mathbf{1 2 / 6 / 6 9 6 7 0}$ for dynamic evaluation of intimal flaps, true and false lumina, entries and reentries, flow patterns and thrombosed channels, native vessels including the supraaortic arteries and the coronary arteries, and the aortic valve.

Therapeutic options now include sealed grafts, sealed composite grafts, biologic glue, ${ }^{6,7}$ glutaraldehyde-preserved xenopericardium, ${ }^{8}$ and improved perfusion techniques. Recent technical modifications in operations for type $\mathrm{A}$ aortic dissections focused on the distal anastomosis, where repair of the aortic $\operatorname{arch}^{9}$ and the advantages of open distal anastomoses have been stressed. However, the type of proximal repair of the ascending aorta is of great interest too, because one of the major perioperative decisions to be made is whether the aortic valve has 


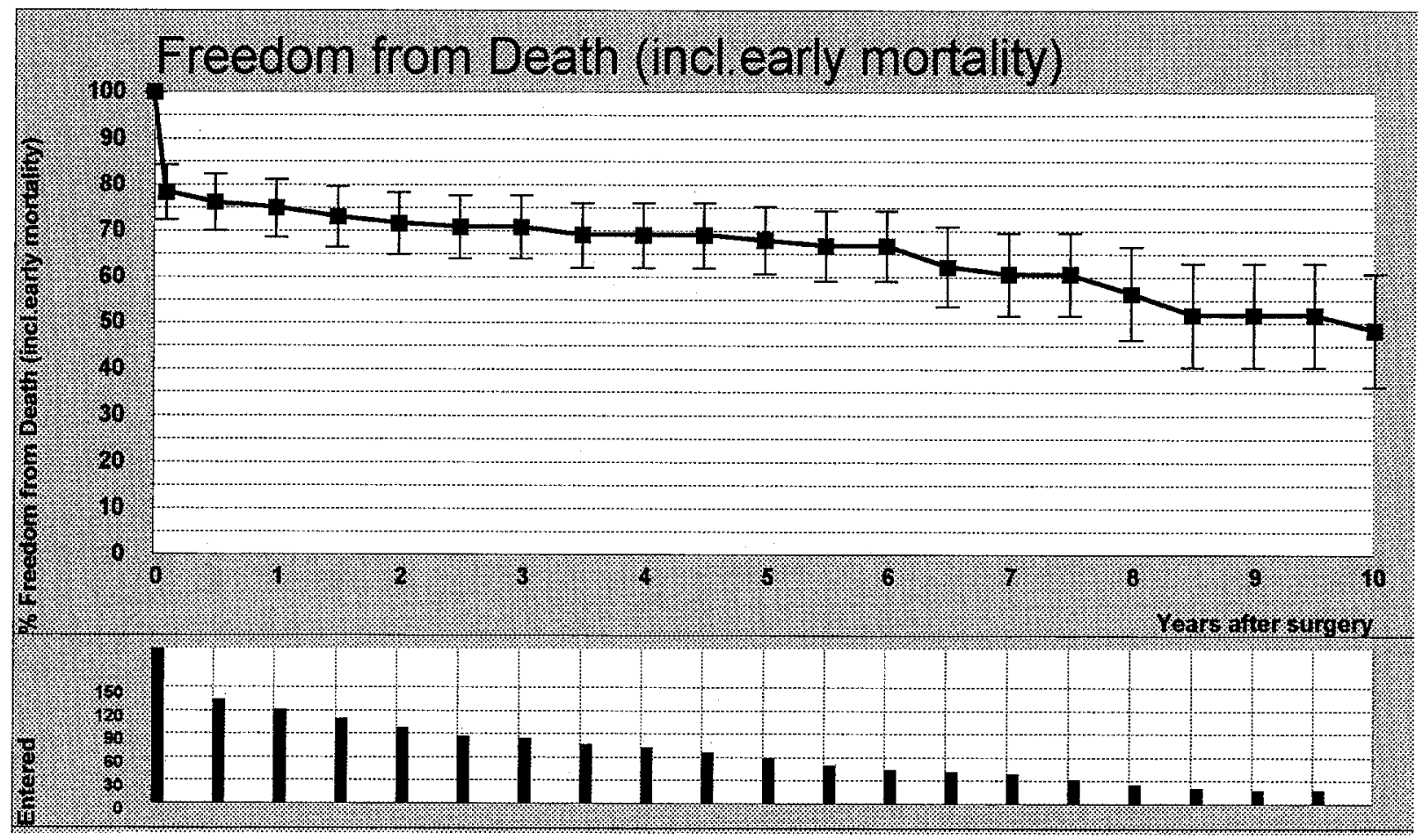

Fig. 1. Actuarial survival probabilities of all patients undergoing operations for acute type A aortic dissection ( $\pm 95 \%$ errors).

Table I. Distribution of patients as a function of the aortic valve and the aortic root, respectively

\begin{tabular}{|c|c|c|c|c|c|c|c|c|}
\hline \multirow[b]{3}{*}{ Type of graft } & \multicolumn{8}{|c|}{ Type of valve } \\
\hline & \multicolumn{2}{|c|}{$A l l$} & \multicolumn{2}{|c|}{ Preserved } & \multicolumn{2}{|c|}{ Mechanical } & \multicolumn{2}{|c|}{ Biologic } \\
\hline & No. & $\%$ & No. & $\%$ & No. & $\%$ & No. & $\%$ \\
\hline All & $200 / 200$ & 100 & $111 / 200$ & 56 & $69 / 200$ & 35 & $20 / 200$ & 10 \\
\hline Supracoronary & $134 / 200$ & 67 & $111 / 200$ & 56 & $18 / 200$ & 9 & $5 / 200$ & 3 \\
\hline Composite & $66 / 200$ & 33 & $0 / 200$ & 0 & $51 / 200$ & 26 & $15 / 200$ & 8 \\
\hline
\end{tabular}

to be replaced or whether it can be preserved or repaired. The present study was performed to establish the long-term outcome of native aortic valves preserved or repaired in situ during operations for acute type A aortic dissections.

\section{Patients and methods}

This study includes a series of 200 consecutive patients undergoing surgical treatment at Zurich University Hospital for acute dissection of the ascending aorta, which is classified type $\mathrm{A}$ in accordance with the guidelines set forth by the Stanford group. ${ }^{3}$ The dissection was defined as acute if chest pain or other symptoms occurred less than 14 days before the operation, as suggested by Fann and colleagues. ${ }^{10}$ If symptoms occurred more than 14 days before the operation, the dissection was termed subacute. Data concerning the procedure were obtained by retro- spective review of hospital records, whereas follow-up information was collected systematically throughout the follow-up period. A final update was achieved by written or telephone contacts with the patients, their families, or their physicians. Follow-up was complete in $94.3 \%$ and totaled 655 patient-years. Mean follow-up was 50 months (maximum 172 months). However, because of the length of the study period, up to 14 years, echocardiographic follow-up was not available for the earlier patients. It was therefore decided not to rely on this incomplete information for valve evaluation and to present only the valve failure data leading to reoperation.

The series of 200 patients analyzed comprised 154 men (77\%) and 46 women (23\%) with a mean age of $55 \pm 6$ years (range 14 to 78 years). Over time, the diagnostic workup has evolved from angiography to computed tomography and finally transesophageal echocardiography. To reduce the delay in diagnosis in the patients with acute 


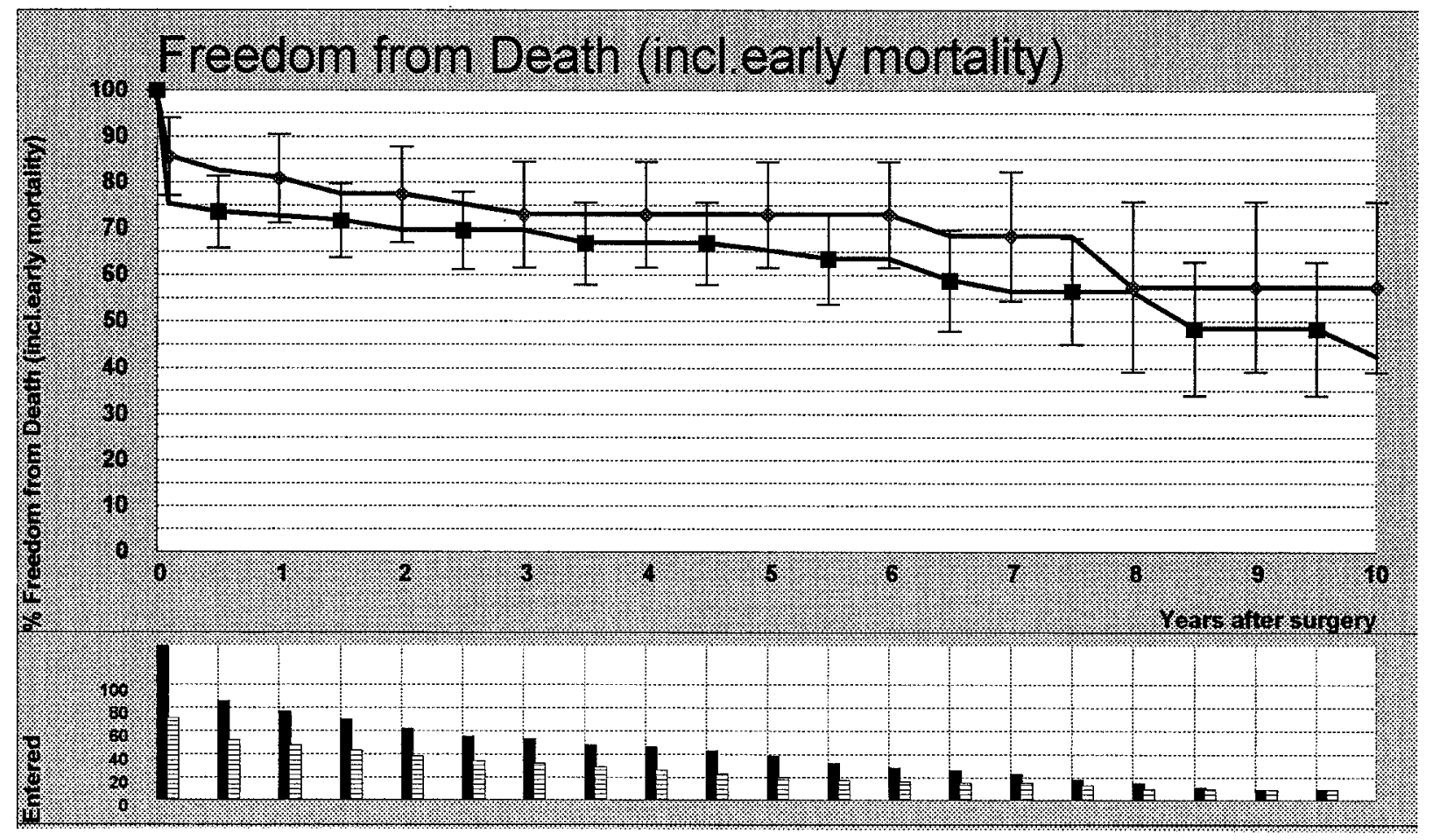

Fig. 2. Actuarial survival probabilities of patients with supracoronary grafts (squares) versus patients with composite grafts (rhombi) ( $\pm 95 \%$ errors). There is no statistically significant difference between groups.

dissection, we now use transesophageal echocardiography as our standard approach. The therapeutic decision is generally based on the patient's history and the echocardiographic findings alone. In this study, acute aortic dissections were diagnosed in 161 of 200 patients $(81 \%)$ and subacute dissection in 39 of 200 patients (19\%).

Information on aortic valve function before the operation was not available in some patients in whom the primary diagnosis was made by computed tomography or angiography, but it was available in 174 patients $(87 \%)$. Among these 174 patients, some degree of aortic incompetence was diagnosed in 57 of 105 patients $(54 \%)$ who had preservation or repair of native aortic valves (estimate of regurgitation $34 \% \pm 14 \%$ ), 35 of 50 patients ( $70 \%$ : no significant difference vs preservation) who had insertion of a composite graft (estimate of regurgitation $49 \% \pm 16 \%$ ), and 13 of 19 patients (68\%: no significant difference vs preservation) with aortic valve replacement and supracoronary graft placement (estimate of regurgitation: $58 \% \pm 14 \%$ ). In these subgroups, acute dissections diagnosed less than 72 hours after the first symptom were operated on in 67 of 105 patients (64\%) with preservation or repair of the native aortic valve, with a composite graft in 24 of 50 patients (48\%: no significant difference vs preservation) and with aortic valve replacement and supracoronary graft placement in 16 of 19 patients (84\%: no significant difference vs preservation).

Surgical technique. In this series the ascending aorta was replaced with a Dacron polyester graft in all patients. The aortic arch was replaced in part or as a whole in 37 of the 200 patients (19\%). The aortic root, however, was handled in three different ways: (1) The aortic valve was preserved, the commissures were repositioned if necessary, and the ascending aortic graft was placed in the supracoronary position. This was our preferred approach and was applied in 111 of the 200 patients $(56 \%)$. (2) The aortic valve was replaced and the ascending aortic graft was sutured in the supracoronary position. This approach was selected in 23 of the 200 patients $(12 \%)$ with a diseased aortic valve (e.g. bicuspid valve) but an acceptable configuration of the aortic sinus portion. (3) The aortic root was replaced with a composite graft (valve plus conduit necessitating reimplantation of the coronary arteries). This procedure was selected in 66 of the 200 patients (33\%), mainly because of an enlarged aortic anulus and sinus portion.

Femoral artery cannulation, median sternotomy approach, total cardiopulmonary bypass, and cold, highpotassium cardioplegic cardiac arrest were standard More recently, biologic glue, retrograde blood cardioplegia, and hypothermic circulatory arrest for open distal anastomosis became routine. Whenever possible, the native aortic valve was preserved or repaired in situ. Construction of a sandwich, the dissected layers of the aortic root being sewn with monofilament sutures between strips of Teflon felt and the ascending aortic graft, was the preferred technique in the earlier part of the study $(100 \%$ at the beginning of the analyzed series). In this group the commissures of the aortic valve were repositioned if necessary and included in the suture of the proximal 


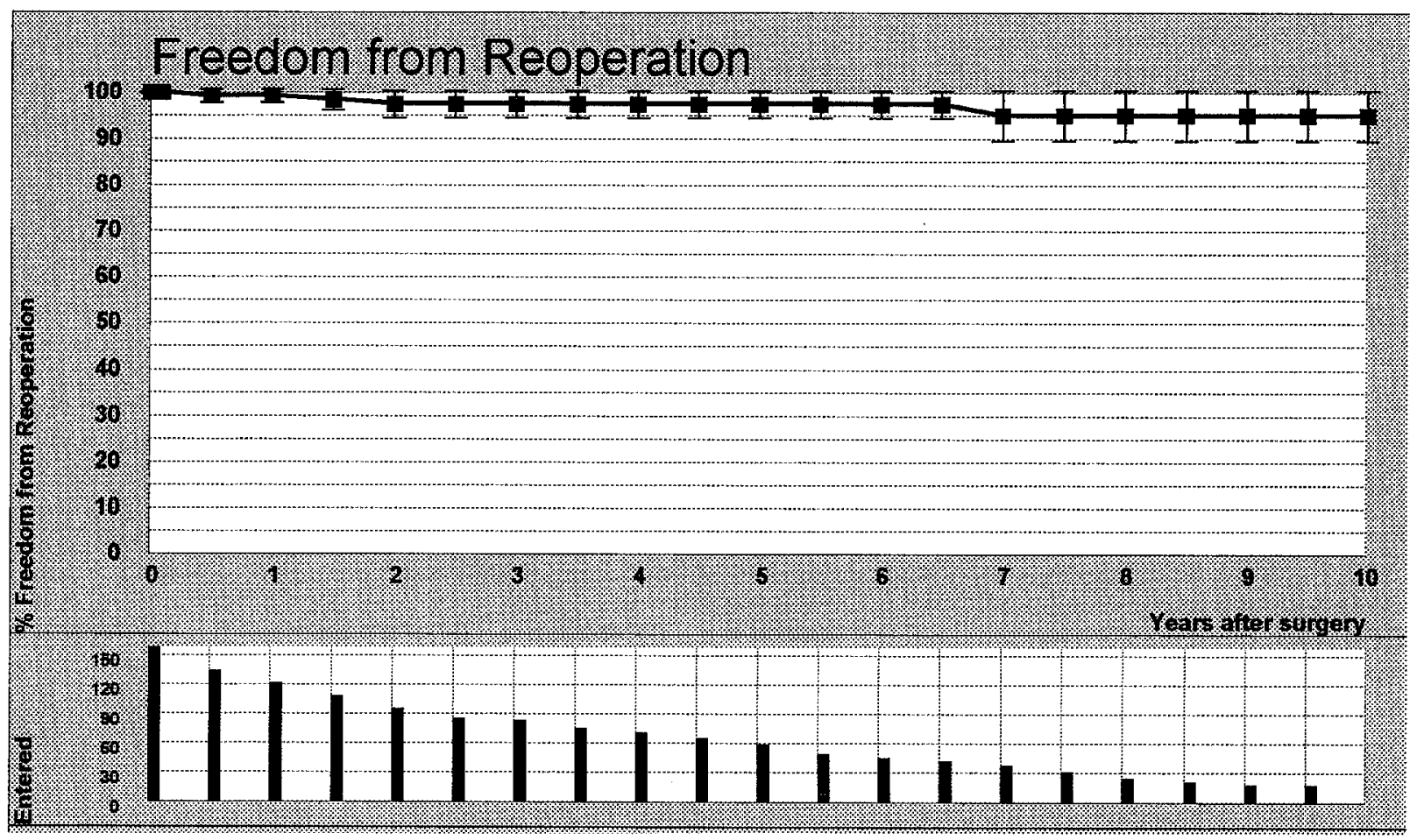

Fig. 3. Actuarial probability of freedom from reoperation for all patients ( $\pm 95 \%$ errors).

Table II. Distribution of all reoperations as a function of type of valve and type of graft

\begin{tabular}{|c|c|c|c|c|c|c|c|c|}
\hline \multirow[b]{3}{*}{ Type of graft } & \multicolumn{8}{|c|}{ Type of valve } \\
\hline & \multicolumn{2}{|c|}{ All } & \multicolumn{2}{|c|}{ Preserved } & \multicolumn{2}{|c|}{ Mechanical } & \multicolumn{2}{|c|}{ Biologic } \\
\hline & No. & $\%$ & No. & $\%$ & No. & $\%$ & No. & $\%$ \\
\hline All & $18 / 200$ & 9 & $11 / 111$ & 10 & $5 / 69$ & 7 & $2 / 20$ & 10 \\
\hline Supracoronary & $13 / 134$ & 10 & $11 / 111$ & 10 & $1 / 18$ & 6 & $1 / 5$ & 20 \\
\hline Composite & $5 / 66$ & 8 & $0 / 0$ & 0 & $4 / 51$ & 8 & $1 / 15$ & 7 \\
\hline
\end{tabular}

All valve-related and non-valve-related surgical procedures during follow-up (reoperations due to structural valve failure are analyzed in actuarial fashion: see Figs, 6 and 7).

anastomosis. More recently, the aortic root was usually repaired with biologic glue after polymerization and allowing for direct suture with or without graft material. This is now our preferred approach $(100 \%$ at the end of the analyzed period). Teflon felt can be avoided in most cases. Commissural resuspension, consolidation, or reduction of the aortic sinus resulting in some type of aortic valve repair was performed 67 of the 111 patients $(60 \%)$ in whom the native aortic valve was preserved.

In the majority of patients with a diseased aortic valve or an enlarged aortic root, the aortic valve was replaced with a bileaflet mechanical device; in a minority, it was replaced with a glutaraldehyde-preserved porcine biologic valve that was carefully rinsed three times before implantation, as recommended by the manufacturer. As a rule, life-long anticoagulation with warfarin sodium (Coumadin) analogs was maintained in patients receiving mechanical aortic valves, whereas low-dose heparin was given during the hospital stay to patients with preserved or repaired native or biologic aortic valves.

Statistical analyses. Statistical analysis was performed for the population as a whole, as well as in accordance with the surgical approach selected-(a) composite graft repair versus (b) aortic valve replacement and supracoronary graft implantation versus (c) aortic valve preservation or repair and supracoronary graft implantation. In addition, the outcome was analyzed as a function of the type of aortic valve at risk. Three groups can be distinguished: patients with a preserved or repaired native aortic valve, patients with a mechanical aortic valve, and patients with a porcine biologic aortic valve. Survival and event-free probabilities plus or minus errors $(95 \%)$ were calculated by actuarial analyses. ${ }^{11-13}$ Student's $t$ test was used for comparison of parametric data and Fisher's exact test for comparison of nonparametric data if applicable. A $p$ value less than 0.05 was considered significant. 


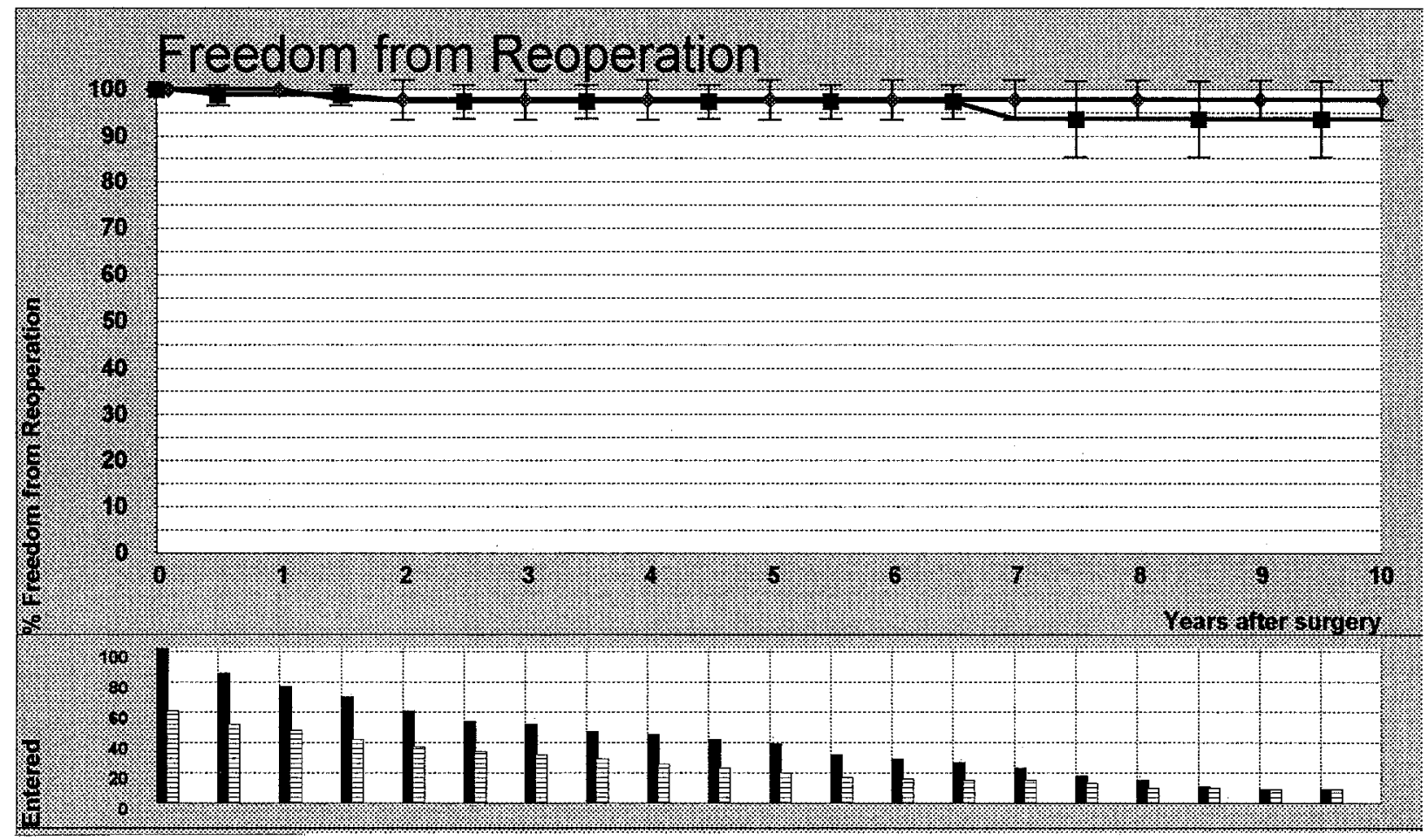

Fig. 4. Actuarial probability of freedom from reoperation for patients with supracoronary grafts (squares) versus those with composite grafts (rhombi) ( $\pm 95 \%$ errors). There is no statistically significant difference between groups.

\section{Results}

Distribution of patients in accordance with the type of valve and the type of aortic graft is shown in Table I. The following analyses are concentrated on the results of the series as a whole (all 200 patients), patients with supracoronary grafting (134/200: 67\%) versus patients with a composite graft (66/200: $33 \%$ ), and patients with a preserved or repaired native aortic valve left in situ (111/200: $56 \%$ ) versus patients with a mechanical aortic valve (69/200: $35 \%$ ) versus patients with a biologic aortic valve (20/200: 10\%).

Survival. Overall actuarial survival probability of the 200 analyzed patients was $78.3 \% \pm 2.9 \%$ after 30 days, $74.9 \% \pm 3.1 \%$ after 1 year, $67.9 \% \pm 3.6 \%$ after 5 years, and $48.5 \% \pm 6.1 \%$ after 10 years (Fig. 1). For patients who underwent supracoronary grafting of the ascending aorta (134/200: 67\%) with or without replacement of the aortic valve, survival was $75.2 \% \pm 3.8 \%$ after 30 days, $71.6 \% \pm 4.0 \%$ after 1 year, $65.2 \% \pm 4.6 \%$ after 5 years, and $42.4 \% \pm 8.5 \%$ after 10 years. The corresponding figures for patients who underwent implantation of a composite graft $(66 / 200$ patients: $33 \%)$ were
$85.6 \% \pm 4.2 \%$ after 30 days, $80.8 \% \pm 4.8 \%$ after 1 year, $72.9 \% \pm 5.7 \%$ after 5 years, and $57.5 \% \pm$ $9.2 \%$ after 10 years (no significant difference among groups (Fig. 2). For the complete series excluding early mortality (158/200 patients: $79 \%)$, 1-year survival was $96.7 \% \pm 1.7 \%$ versus $86.8 \% \pm 3.3 \%$ after 5 years and $61.9 \% \pm 7.5 \%$ after 10 years. For early survivors of supracoronary grafting (102/158: $65 \%)$, 1 -year survival was $96.6 \% \pm 1.9 \%$ versus $86.7 \% \pm$ $4.3 \%$ after 5 years and $56.4 \% \pm 10.9 \%$ after 10 years. The corresponding figures for early survivors with a composite graft (56/158: $35 \%)$ were $94.5 \% \pm 3.1 \%$ after 1 year, $85.3 \% \pm 5.2 \%$ after 5 years, and $67.2 \% \pm 10.2 \%$ after 10 years (no significant difference among groups).

Reoperations. Eighteen reoperations were performed for various reasons in the 200 patients (9\%). Indications for reoperations included structural and nonstructural valve failure (10/18: 56\%), progression of dissection or aneurysm (6/18: $33 \%)$, and suture dehiscence resulting in development of a false aneurysm (2/18: 11\%). Distribution of reoperations as a function of the analyzed groups is detailed in Table II. The proportion of redo operations for 


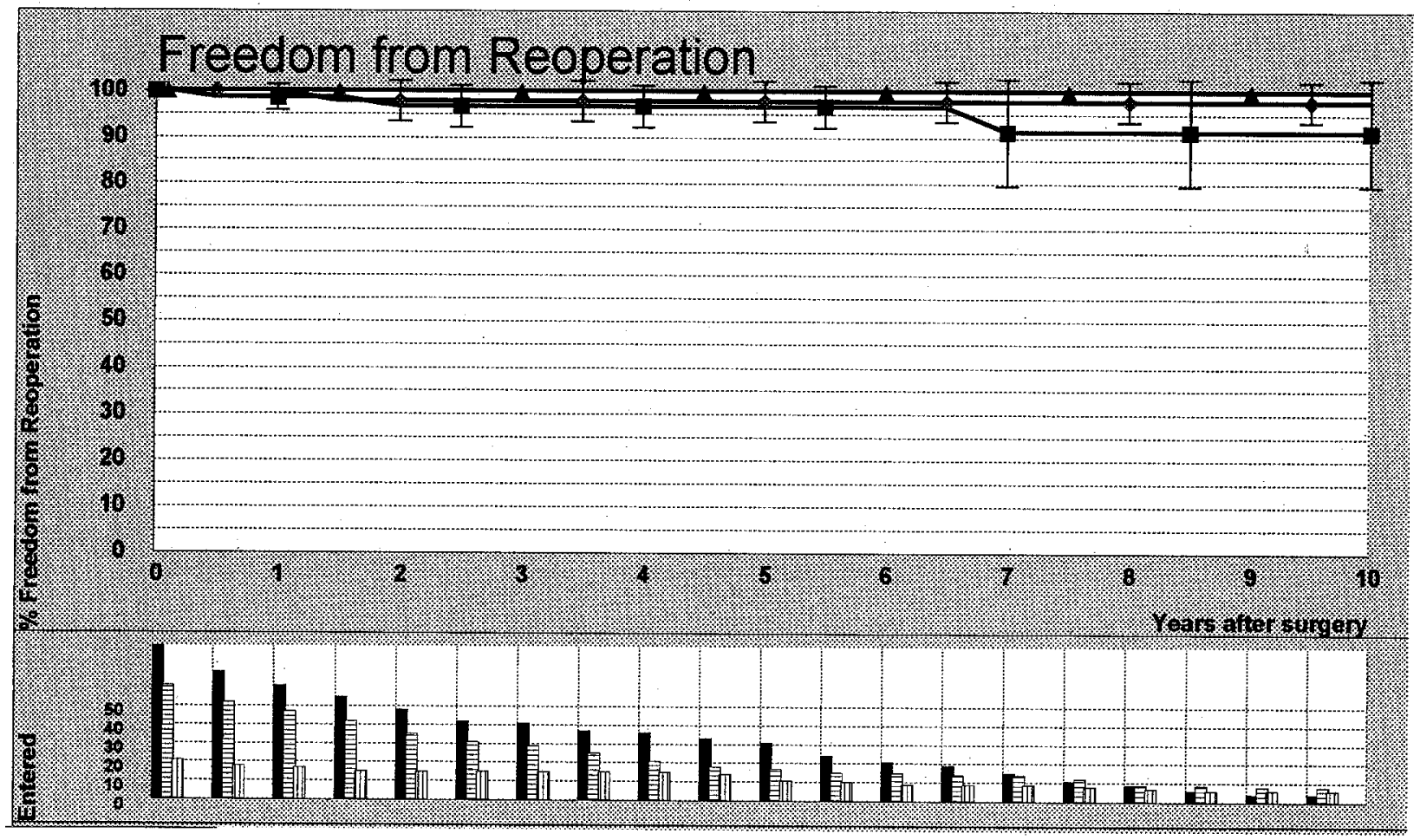

Fig. 5. Actuarial probability of freedom from reoperation for patients with preserved or repaired aortic valves (squares) versus those with mechanical aortic valves (rhombi) versus those with biologic aortic valves (triangles) ( $\pm 95 \%$ errors). There is no statistically significant difference among groups.

the main groups was 13 of $134(10 \%)$ in patients with a supracoronary graft, 5 of $66(8 \%)$ for patients with a composite graft, 11 of $111(10 \%)$ for patients with a preserved or repaired native aortic valve, 5 of 69 (7\%) for patients with a mechanical valve, and 2 of $20(10 \%)$ for patients with a biologic valve.

Ten reoperations were performed for structural and nonstructural valve failure (10/200: $5 \%$ ): 6 of $111(5 \%)$ in the group with a preserved or repaired native aortic valve, 3 of $69(4 \%)$ in the group with a mechanical aortic valve, and 1 of $20(5 \%)$ in the group with a biologic aortic valve. Only reoperations for structural valve failure were considered for the following actuarial analyses: Probability of actuarial freedom from reoperation for structural valve failure in the complete series (158/200 patients: $79 \%)$ was calculated as $100.0 \% \pm 0.0 \%$ after 30 days, $99.3 \% \pm 0.7 \%$ after 1 year, $97.5 \% \pm 1.5 \%$ after 5 years, and $95.1 \% \pm 2.8 \%$ after 10 years (Fig. 3). For early survivors with a supracoronary graft (102/158 patients: $65 \%$ ), actuarial freedom from reoperation was $100.0 \% \pm 0.0 \%$ after 30 days, $98.9 \% \pm 1.1 \%$ after 1 year, $97.4 \% \pm 1.8 \%$ after 5 years, and $93.6 \% \pm 4.1 \%$ after 10 years. For early survivors with a composite graft (56/158 patients: $35 \%$ ), freedom from reoperation was $100.0 \% \pm 0.0 \%$ after 30 days and 1 year, $97.8 \% \pm 2.2 \%$ after 5 years, and $97.8 \% \pm 2.2 \%$ after 10 years (no significant difference among groups) (Fig. 4).

For early survivors in whom the native aortic valve was preserved or repaired (82/158 patients: $52 \%$ ), freedom from reoperation for valve failure was $100.0 \% \pm 0.0 \%$ after 30 days, $98.6 \% \pm 1.4 \%$ after 1 year, $96.7 \% \pm 2.3 \%$ after 5 years, and $91.2 \% \pm$ $5.8 \%$ after 10 years. For early survivors with a mechanical valve (57/158 patients: $36 \%$ ), the corresponding figures were $100.0 \% \pm 0.0 \%$ after 30 days and 1 year, $97.8 \% \pm 2.2 \%$ after 5 years, and $97.8 \% \pm 2.2 \%$ after 10 years. For early survivors who received a biologic valve (19/158 patients: $12 \%$ ), freedom from reoperation for valve failure was $100.0 \% \pm 0.0 \%$ at 30 days, 1 year, 5 years, and 10 years of follow-up (no significant difference among groups) (Fig. 5).

Other complications. Freedom from thromboembolism for all early survivors (158/200 patients: $79 \%$ ) was $98.0 \% \pm 1.1 \%$ after 30 days, $98.0 \% \pm$ $1.1 \%$ after 1 year, $96.8 \% \pm 1.7 \%$ after 5 years, and 


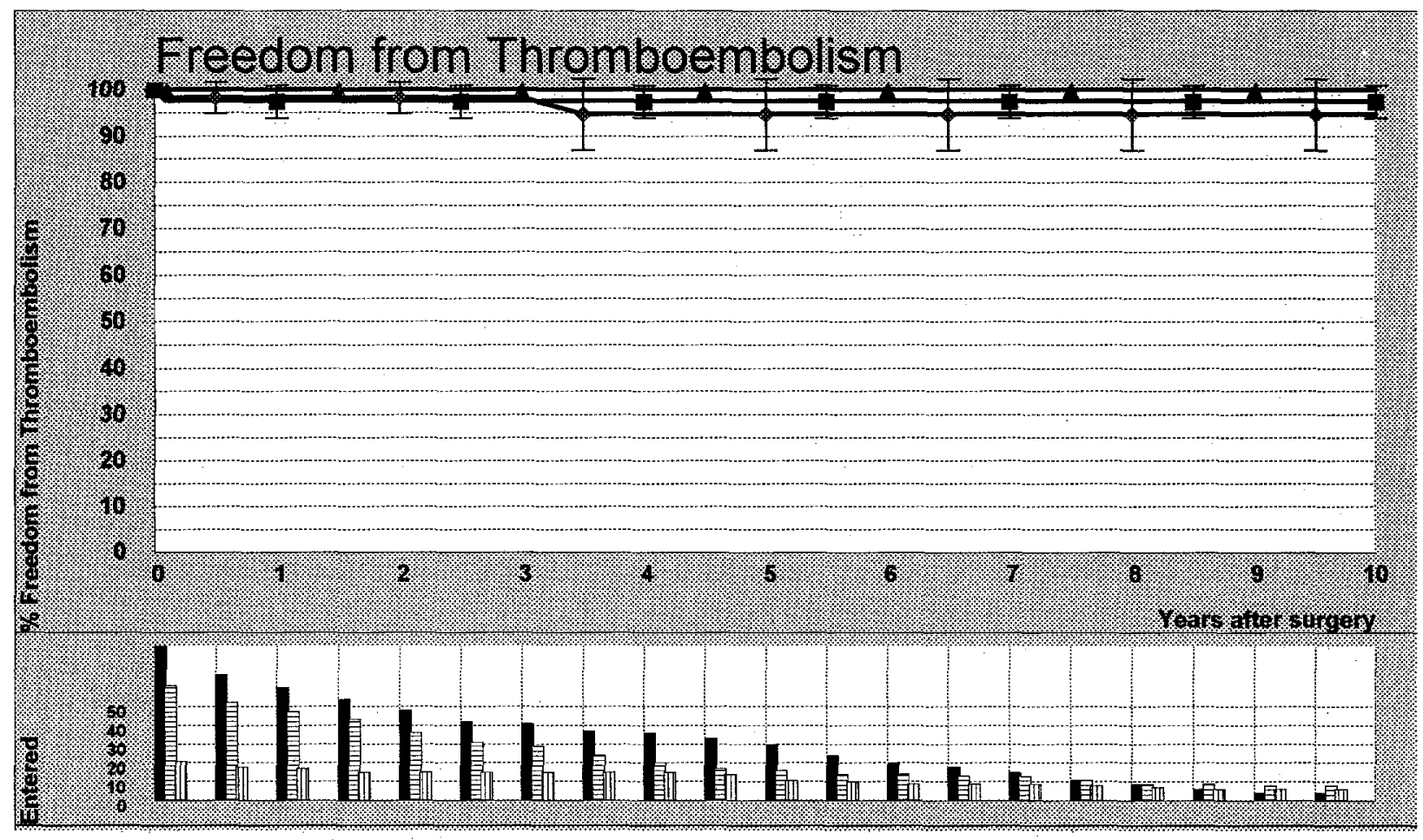

Fig. 6. Actuarial freedom from thromboembolism for patients with preserved or repaired native aortic valves (squares) versus those with mechanical aortic valves (rhombi) versus those with biologic aortic valves (triangles) ( $\pm 95 \%$ errors). There is no statistically significant difference among groups.

$96.8 \% \pm 1.7 \%$ after 10 years. For early survivors with a preserved or repaired native aortic valve (82/158 patients: $52 \%$ ), freedom from thromboembolism was $97.5 \% \pm 1.8 \%$ after 30 days, 1 year, 5 years, and 10 years. For patients a with mechanical valve $(57 / 158$ patients: $36 \%)$, the corresponding figures were $98.3 \% \pm 1.7 \%$ after 30 days and 1 year and $94.7 \% \pm 3.9 \%$ after 5 and 10 years. No thromboembolic complications were observed in the few patients with biologic valves (no significant difference among groups) (Fig. 6). No hemorrhage related to anticoagulation was recorded in either group, and neither thrombotic occlusion nor endocarditis was documented.

Late events. Late events including valve failure, reoperation, thromboembolic events, thrombotic valve obstruction, anticoagulant-related hemorrhage, endocarditis, and others are summarized here. Freedom from late events for all early survivors $(158 / 200$ patients: $79 \%)$ was $93.3 \% \pm 2.1 \%$ after 1 year, $87.8 \% \pm 3.1 \%$ after 5 years, and $83.3 \% \pm 4.3 \%$ after 10 years. Freedom from late events for patients with supracoronary aortic grafts (82/158 patients: $52 \%)$ was $91.6 \% \pm 2.9 \%$ after
1 year, $88.3 \% \pm 3.6 \%$ after 5 years, and $81.3 \% \pm$ $6.8 \%$ after 10 years. For patients with composite grafts (56/158: $35 \%)$, the respective figures were $96.6 \% \pm 2.3 \%$ after 1 year and $87.5 \% \pm 5.6 \%$ after 5 years and 10 years (no significant difference among groups) (Fig. 7).

Analysis as a function of the type of valve in the aortic position provided the following probabilities: In early survivors with a preserved or repaired native aortic valve (82/158 patients: $52 \%$ ), freedom from late events was $89.5 \% \pm 3.5 \%$ after 1 year, $85.3 \% \pm$ $4.5 \%$ after 5 years, and $75.5 \% \pm 7.6 \%$ after 10 years. For early survivors with a mechanical aortic valve (57/158 patients: $36 \%$ ), freedom from late events was $96.6 \% \pm 2.4 \%$ after 1 year and $90.9 \% \pm 4.6 \%$ after 5 and 10 years. For early survivors with a biologic aortic valve (19/158 patients: $12 \%)$, the respective figures were $95.0 \% \pm 4.9 \%$ after 1 year and $88.5 \% \pm 7.8 \%$ after 5 and 10 years (no significant difference among groups) (Fig. 8).

\section{Discussion}

During repair of acute type A aortic dissections, preservation or repair of the native aortic valve can 


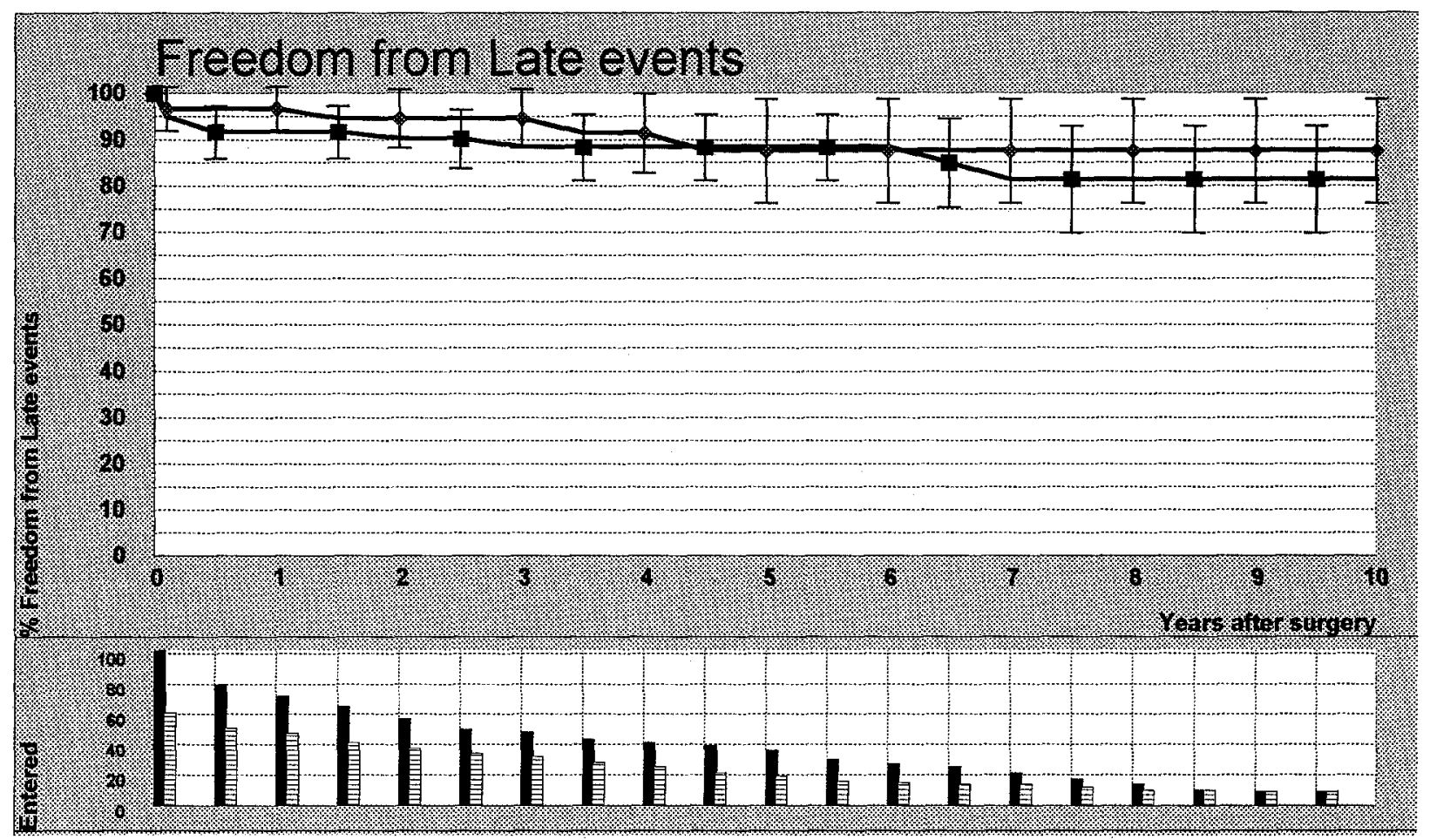

Fig. 7. Actuarial freedom from late events for patients with supracoronary grafts (squares) versus those with composite grafts (rhombi) ( $\pm 95 \%$ errors). There is no statistically significant difference between groups.

be recommended for the majority of patients. This study demonstrates that throughout the follow-up period of more than 10 years, the performance of preserved or repaired native aortic valves left in situ was adequate. All analyzed parameters including freedom from structural and nonstructural valve failure resulting in reoperation, freedom from thromboembolic events, freedom from anticoagulant-related hemorrhage, and freedom from endocarditis were similar for the three analyzed aortic valve types, namely, native repaired aortic valves, mechanical devices, and biologic devices (see also Fig. 5). Although the number of biologic valves used is relatively small, this group is interesting to observe because anticoagulation can be avoided, as in native repaired aortic valves. Instances of thromboembolism are analyzed in Fig. 6, which clearly shows that there are no differences between native and repaired aortic valves versus mechanical devices versus biologic devices. In addition, no instances of thrombotic occlusion or anticoagulant-related hemorrhage occurred in either group. Compilation of late events and graphic layout in Fig. 8 demonstrates that the curves illustrating actuarial freedom from late events have overlapping error bars, which again preclude significant differences among the three types of valves analyzed.

These findings confirm previous work by the Stanford group, ${ }^{10}$ who reported reoperations for valve failure in 2 of 46 patients (4\%) with resuspension and in 4 of 75 patients $(5 \%)$ with previous valve replacement (no significant difference). Freedom from aortic valve replacement at 5 and 10 years in their series was $100 \%$ and $80 \% \pm 13 \%$ for resuspension versus $98 \% \pm 2 \%$ and $73 \% \pm 13 \%$ for initial aortic valve replacement. We agree with the authors' conclusion stating satisfactory durability of aortic valve resuspension, coupled with the absence of potential complications related to the prosthetic valve and need for indefinite anticoagulation.

With regard to reoperation, in the series of 32 patients reported on by Bachet and associates, ${ }^{14}$ only four of 42 redo operations were done for valve disease $(10 \%)$. In their series, the main reason for reoperation was evolution of aneurysmal disease, an observation that confirms again that function of repaired native aortic valves is generally good. Preservation of the aortic valve in acute aortic dissection 


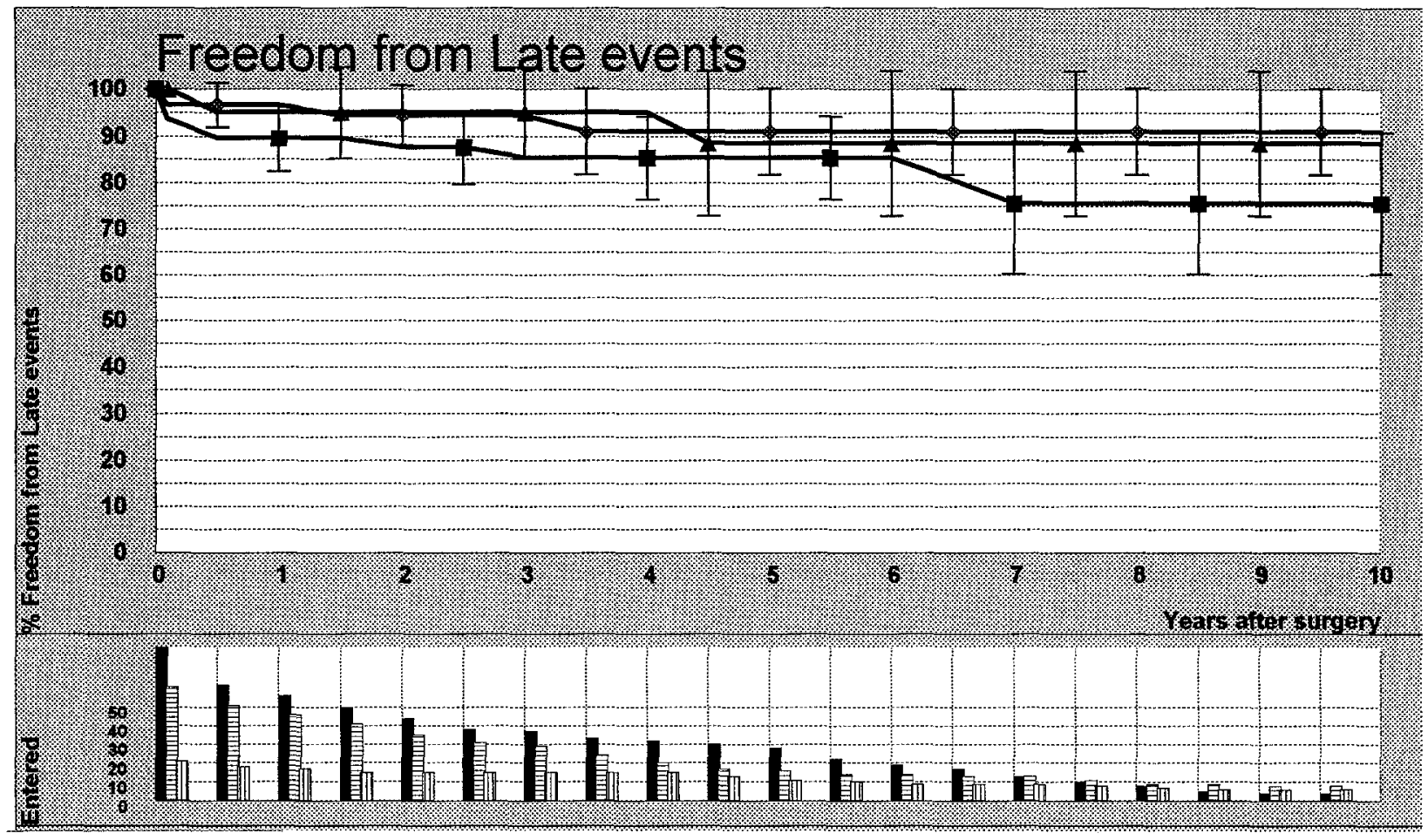

Fig. 8. Actuarial freedom from late events for patients with preserved or repaired native aortic valves (squares) versus those with mechanical aortic valves (rhombi) versus those with biologic aortic valves (triangles) ( $\pm 95 \%$ errors). There is no statistically significant difference among groups.

was also analyzed by Mazzucotelli and colleagues. ${ }^{15}$ They found actuarial freedom from aortic valve reoperation in $83 \% \pm 6 \%$ at 5 years and $79 \% \pm 7 \%$ at 10 years. In their series, echocardiographic follow-up studies showed no or mild aortic insufficiency in 22 of 41 patients $(54 \%)$ and moderate aortic insufficiency with satisfactory left ventricular function in 12 of 41 patients (29\%). Overall, aortic valve replacement was necessary in 8 patients of their series, and they are included in the actuarial reoperation rates mentioned. Actuarial survival in their series was $63 \% \pm 6 \%$ at 5 years, $55 \% \pm 7 \%$ at 10 years, and $39 \% \pm 9 \%$ at 15 years for patients with a repaired aortic valve. For hospital survivors, the respective figures were $83 \% \pm 6 \%$ after 5 years and $79 \% \pm 9 \%$ after 10 years. These figures are similar to those of early survivors who underwent supracoronary grafting in the series presented here.

The results of our series and those cited from the literature, as recently compiled by Grunkemeier and Bodnar, ${ }^{16}$ show that native aortic valves preserved or repaired during operations on the ascending aorta for cure of type A dissection perform at least as well as the various bioprostheses used for simple aortic valve replacement.

Regardless of the aortic valve repair or replacement technique selected, ${ }^{17}$ evaluation of aortic valve competence, left ventricular function, and aortic wall expansion are warranted at regular intervals during long-term follow-up of all patients with a history of aortic dissection. The known risk factors for the primary event, namely, systemic hypertension, the Marfan syndrome, congenitally bicuspid or unicommissural valves, and to a lesser degree aortic medial degeneration and rupture of ulcerocalcific atheromas, ${ }^{18}$ may also play a role in secondary events at the same site or at another aortic site distant from the primary lesion. ${ }^{19}$

\section{REFERENCES}

1. De Bakey ME, Cooley DA, Creech O. Surgical considerations of dissecting aneurysm of the aorta. Ann Surg 1955;142:586-612.

2. Dubost C, Guilmet D, Soyer R. La chirurgie des anéurysmes de l'aorte. Paris: Masson et Cie, 1970: $247-9$. 
3. Daily PO, Trueblood HW, Stinson EB, et al. Management of acute aortic dissections. Ann Thorac Surg 1970;10:237-47.

4. Rizzo RJ, Aranki SF, Aklog L, et al. Rapid noninvasive diagnosis and surgical repair of acute ascending aortic dissection: improved survival with less angiography. J Thorac Cardiovasc Surg 1994;108:567-75.

5. Simon P, Owen AN, Havel M, et al. Transesophageal echocardiography in the emergency surgical management of patients with aortic dissection. J THORAC CardiovasC Surg 1992;103:1113-8.

6. Guilmet D, Laurian C, Gigou F. La colle gélatinerésorcine-formaldehyde en chirurgie vasculaire. Nouv Presse Med 1977;6:3221-3.

7. von Segesser LK, Oechslin E, Jenni R, Turina MI. Use of glue to avoid formation of perfused recesses in aortic allograft implantation. Ann Thorac Surg 1994; 57:494-5.

8. von Segesser LK, Cox J, Simonet F, Faidutti B, Turina M. Die Verwendung von equinem glutaraldehydfixiertem Pericard in heterotoper Position. Helv Chir Acta 1988;55:153-6.

9. Crawford ES, Kirklin JW, Naftel DC, et al. Surgery for acute dissection of ascending aorta: Should the arch be included? J Thorac Cardiovasc Surg 1992; 104:46-59.

10. Fann JI, Glower DD, Miller DC, et al. Preservation of aortic valve in acute type $A$ dissection complicated by aortic valve regurgitation. $J$ THORAC CARDIOVASC SURG 1991;102:62-75.

11. Cutler SJ, Ederer F. Maximum utilization of the life table method in analyzing survival. J Chron Dis 1958;8:699-712.

12. Kaplan EL, Meier P. Nonparametric estimation from incomplete observations. J Am Stat Assoc 1958;53: 457-81.

13. Blackstone EH. Aanlysis of death (survival analysis) and other time related events. In: Congenital heart disease. Macartney FJ, ed. Dordrecht: MTP Press, 1986:55-101.

14. Bachet JE, Termignon JL, Dreyfus G, et al. Aortic dissection: prevalence, cause, and results of late reoperation. J Thorac CARdiovasc Surg 1994;108:199. 206.

15. Mazzucotelli JP, Deleuze PH, Baufreton C, et al. Preservation of aortic valve in acute aortic dissection: long-term echocardiographic assessment and clinical outcome. Ann Thorac Surg 1993;55:1513-7.

16. Grunkemeier GL, Bodnar E. Comparartive assessment of bioprosthesis durability in the aortic position. J Heart Valve Disease 1995;4:49-55.

17. Svensson LG, Crawford ES, Hess KR, Coselli JS, Safi HJ. Composite valve graft replacement of the proximal aorta: comparison of techniques in 348 patients. Ann Thorac Surg 1992;54:427-39.

18. Larson EW, Edwards WD. Risk factors for aortic dissection: a necropsy study of 161 cases. Am J Cardiol 1984;53:849-55.

19. von Segesser LK, Killer I, Ziswiler M, et al. Dissection of the descending thoracic aorta extending into the ascending aorta: a therapeutic challenge. J THORAC Cardiovasc Surg 1994;108:755-61.

\section{Discussion}

Mr. Stephen Westaby (Oxford, England). The study period covers a time during which surgical techniques in aortic dissection changed considerably. I would like to concentrate my remarks specifically on the long-term integrity of valve repair, because the surgical methods have changed from suspension with Teflon pledgets to the use of glue in Europe.

I have one criticism of the study design. The authors did not differentiate the degree of aortic regurgitation for their individual patients but collectively assessed the outcome for all patients who did not receive a prosthetic valve.

In practice, only $40 \%$ to $60 \%$ of patients with acute type A dissection have moderate or severe aortic regurgitation. A large number do not have significant aortic regurgitation. This begs the question whether it is valid to determine the efficacy of valve repair without detailed preoperative and postoperative assessment of aortic regurgitation in individual patients.

I would like to bring to your notice a series of 170 patients with acute type A dissection. The Stanford and Duke groups believed that a procedure to repair or replace the aortic valve was necessary in only 75 of them. Their judgment was that the aortic valve was sound in the majority of their patients. In your study the patients with mild or absent aortic regurgitation are included in the overall numbers of patients having valve repair.

In Europe the availability gelatin-resorcin-formol and fibrin glues has changed the conduct of surgery for type A dissection very considerably. I suspect that in Zurich glue was used predominantly in the latter half of the investigation. Comparing 100 cases from Oxford in the past 8 years (predominantly in the glue era), we were able to repair the aortic valve in $84 \%$ of patients with acute type A dissection. With an increasing number of valve repairs and fewer replacements, the hospital mortality in Oxford has dropped progressively, and we have also found that the valve repair is sound over the long term.

Dr. von Segesser, what has been the influence of glue on the rate of repair and the long-term integrity of the aortic sinuses in the patients treated for aortic dissection?

Dr. von Segesser. We have tried to analyze the results of this series as a function of aortic incompetence or regurgitation. Unfortunately, it is difficult to assess the regurgitation fraction in patients who underwent only computed tomographic scan before the operation. On the other hand, nowadays with transesophageal echocardiography we detect some degree of regurgitation in almost all patients. Thus because of the long time period analyzed, from 1979 to 1992, and the substantially modified techniques of evaluation, we could not reliably assess the degree of regurgitation. That is why we distinguished only 
the type of tissue left in place finally-native, biologic, or mechanical.

The importance of glue has been increasing in the surgical treatment of patients with this disease. Initially, of course, we used Teflon felt strips and pledgets to repair these lesions. Now, we do not merely repair the valve. Rather, in a substantial number of cases, the repair can be effected entirely with the use of glue, and no graft is used. I could not continue with this study because after 1992 a substantial number of the patients had no graft inserted.

Dr. Hans G. Borst (Hannover, Germany). This is one of the largest and best studied groups of patients with acute type A dissection worldwide. The authors' reoperation rate of only $5 \%$ at 10 years after aortic valve reconstruction in acute dissection is a remarkable result. Dr. von Segesser's data confirm our view that the great majority of aortic valves can be preserved in acute proximal dissection, thereby avoiding valve replacement. The risk of anticoagulant-related bleeding in dissection is much greater than in the normal population, of course, because aneurysmal disease tends to develop elsewhere in these patients.

Postoperative failures of these valve reconstructions (not supracommissural grafting) do occur and, in our experience, fall into one of two categories: (1) breakdown of the surgical repair and (2) failure of the physician to properly assess the underlying root disease. Thus, in our experience with 80 patients surviving valve resuspension in the acute stage during the past 15 years, seven subsequently required reoperation for aortic regurgitation. In three the repair had disrupted, and in another two root ectasia had developed in the midterm. In one case both mechanisms were present, and an additional patient had a leaflet defect that probably had been overlooked at the primary operation.

As our experience with acute dissection has increased, we have been able to avoid disruption of the original repair entirely by using advanced techniques of commissural resuspension. In our hands, this now includes routine gelatin-resorcin-formol gluing of the aortic wall layers. Regardless of this aspect, my message here is that the aortic root must be carefully examined for even discrete ectasia. In case of doubt and in all patients with known or suspected connective tissue disorders, the root should be replaced. The newer alternative to replacement, of course, is Dr. Tirone David's root remodeling procedure, which we also use in acute dissection in patients who are in otherwise stable condition.

Dr. von Segesser, which types of valves are you presently excluding from reconstruction?

Dr. von Segesser. We repair valves that were healthy before dissection and we use composite graft repair in patients with enlarged roots. Of course, a patient with full-blown Marfan's syndrome would have a composite graft repair in this type of setting. However, there are a number of patients in whom it is not clear if Marfan's syndrome is really present. In these patients, if the aortic root has an acceptable configuration and diameter, we would attempt repair initially.

Dr. Aubrey C. Galloway (New York, N.Y.). We have a similar series of more than 100 patients having repair of type A dissection since 1985. In that group we have been able to reconstruct more than $90 \%$ of the valves in patients with significant aortic insufficiency. We think it is very important to reconstruct the entire sinotubular junction, much as one does for the distal end of a freehand homograft. If that is done in a 360-degree fashion, most valves are correctable. The noncoronary sinus can be obliterated by taking a tongue of the graft down close to the anulus. Only a small group of our patients, less than $5 \%$, required aortic root replacement. I noticed in your series that $33 \%$ required this procedure. What are the specific criteria for replacing the root? Is it true annuloaortic ectasia with displacement of the coronaries or are you instead replacing some roots in which only the noncoronary sinus is distorted? If so, we think most of those can be repaired.

Finally, I have a last small but important criticism. I think it is impressive that actuarial data suggest a $5 \%$ reoperation rate at 10 years, but what was the mean follow-up interval and how many patients do you actually have in the repair group at 5 years and at 10 years? This information obviously would be important for us to know to weigh your data appropriately.

Dr. von Segesser. The original group of 150 surviving patients was followed up for 172 months maximum. Mean follow-up was 50 months. At 10 years of follow-up there were 20 patients in the overall group. Corresponding figures are given in the article for every time segment in every subgroup. After 7 years of follow-up there are fewer than 10 patients in some groups. Therefore, the reliability of the actuarial analysis and comparisons of these groups is no longer very good, and not too much attention should be paid to these differences.

With regard to root replacements, we consider it necessary for significant enlargement of the anulus or for significant enlargement of the sinus portion of the ascending aorta. In all of the other cases the root can be repaired. With the gluing technique the ascending aorta can be reconstructed so that there is no visible difference between the normal aorta and the glued aorta after this procedure. 